\title{
La reciente encuesta de Opinión Pública de la UTEC
}

En este número Entorno, publica los resultados de la XXVI encuesta de opinión pública, realizada del 1 al 3 de marzo del 2002, por el Centro de Investigación de la Opinión Pública Salvadoreña de la Universidad Tecnológica de El Salvador (CIOPS).

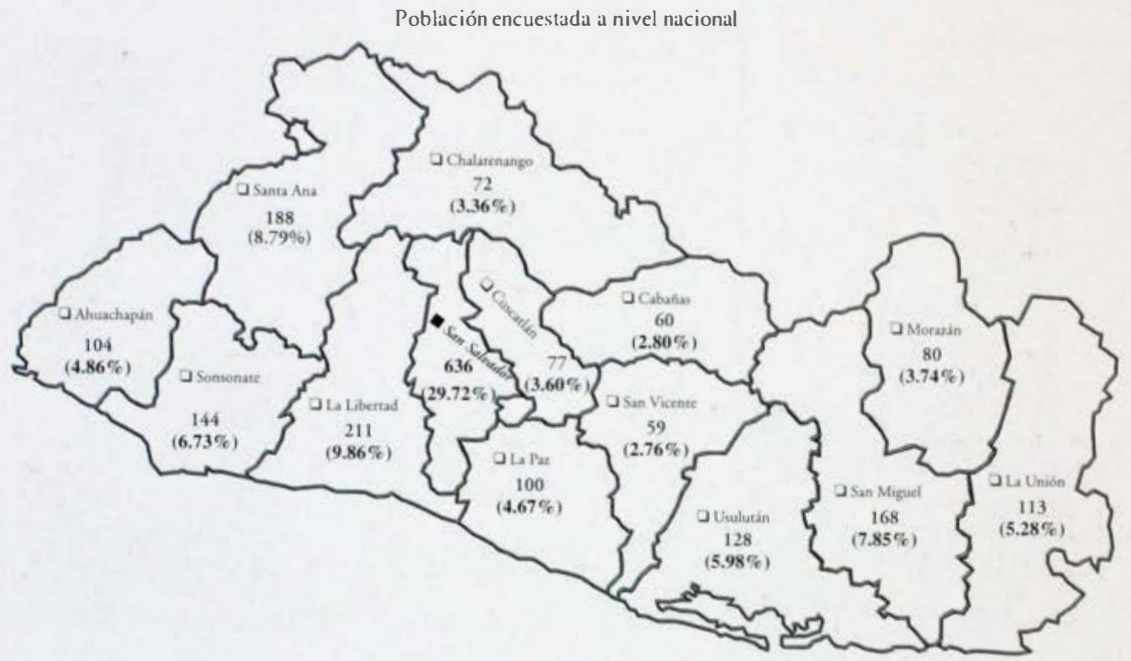

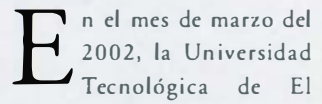

Salvador realizó otra de sus tradicionales encuestas, cuyo objecivo declarado era conocer la opinión de los ciudadanos sobre la situación social, económica y política, así como sobre el tercer año de gestión del Presidente Francisco Flores.

Generalmente la lectura de los resultados deja por fuera intcresantes relaciones causales, que solamente son posibles cuando se da a las respuestas frias y cuantitativas, una estructuración para el análisis político de las mismas. Cada tendencia mostrada en las respuestas de las preguntas es un indicador, pero la vinculación de los indicadores pertenece al campo de la interpretación.

Los resultados de la encuesta bien valen la pena ser interpretados. participamos y partimos de la creencia que, no interpretarlos significaría echar por la borda el esfuerzo de haberla hecho. Esta es una interpretación y no responde a criterios institucionales sino que es responsabilidad de la interpretación política que se da a las cif ras publicadas.

\section{La encuesta}

Cuando se pregunta que se seleccione los problemas más graves que enfrenta nuestro país se destaca el alto costo de la vida, "todo carom, en un 33 por ciento. Luego en un 47 por ciento se mencionan tres problemas de 
indole social que afectan la vida cotidiana de los centros urbanos, pero especialmente San Salvador: maras, alcoholismo y drogadicción $y$ secuestros, problemas que no son ajenos a la realidad de la pobreza, el desempleo y el desajuste social de una sociedad en crisis.

En otro bloque de respuestas, los bajos salarios inciden en un 35 por ciento y la delincuencia, señalada en términos generales, alcanza un 28 por ciento.

Finalmente un tercer bloque de entrevistados dicen que es el desempleo su mayor problema en un 39 por ciento, seguido de narcotráfico $y$ corrupción en un 32 por ciento.

Las respuestas anteriores tienen una vinculación lógica. Desempleo, bajos salarios y alto costo de vida son los detonantes de la pobreza; la pobreza es el detonante de la delincuencia, la violencia y los desajustes sociales. Las sociedades pobres son sociedades enfermas, que buscan, independientemente de criterios éticos, morales y religiosos, salidas a sus problemas y sus insatisfacciones. El estomago lleno o medio lleno, permite que el ser humano pueda darle vía a otras actividades humanas $y$ sociales, entre ellas pensar, tener religión y respetar los derechos de los demás.

Varios estudios han señalado que uno de los problemas más graves del país es el desempleo, $y$ en la medida que las familias carecen de ingresos para atender sus necesidades, se producen ef ectos negativos en varios sentidos, pero especialmente en la imposibilidad de atender sus necesidades básicas, en

\section{Encuesta de opinión pública XXVI

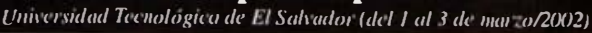

\section{Localización}

Urbana 1444 (67.48\%)

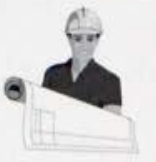

Rural

$696(32.52 \%)$

\section{Sexo}

Masculino 1063 (49.67\%)
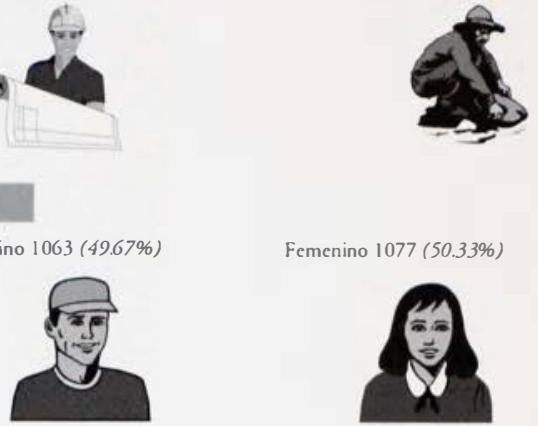

Femenino 1077 (50.33\%)

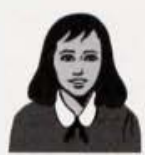

\section{Estado civil}

$\begin{array}{ll}\text { Solcero } & 984(45.98 \%) \\ \text { Casado } & 757(35.37 \%) \\ \text { Acompañado } & 302(14.11 \%) \\ \text { Divorciado } & 33(1.54 \%) \\ \text { Viudo } & 49(2.29 \%) \\ \text { Sin Opinión } & 15(0.70 \%)\end{array}$

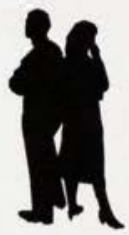

Edad

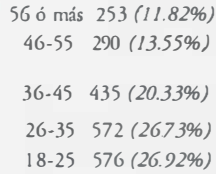

S.O. $14(0.65 \%)$

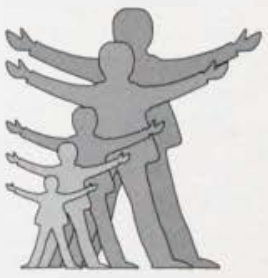

\section{Escolaridad}

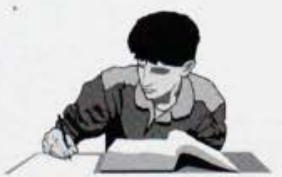


el desarrollo dela vida en condiciones de pobreza extrema y en los hechos y conductas de la sociedad para suplir los ingresos: drogas, prostitución, violencia y delincuencia en general.

El 73 por cicnto de los entrevistados no creen que el Gobierno esté resolviendo los problemas del país; el 89 por ciento considera que el país evidentemente se encuentra viviendo una crisis, y el 54 por ciento dice que son los aspectos económicos los directamente responsables de la crisis. Lostres puntos están relacionados: falta de empleo que crea dificiles condiciones económicas, y un gobierno que el pueblo no siente que esté haciendo algo para solucionar dicha situación.

Dentro de las preguntas se introduce la obligada apreciación sobre los orígenes que, a juicio del entrevistado, se constituyen en la causa principal de la crisis. En un 44 por ciento se hace responsable al desempleo, y en un 32 por ciento se señala a la desintegración familiar. Las respuestas no son conceptualmente coincidentes, la desintegración familiar puede estar ocasionada a su vez por otras causas: incapacidad de responder a las obligaciones familiares, carencia de valores de familia, juventud $e$ inexperiencia, ir responsabilidad, sexo, pobreza, migración obligada y otras muchas opciones. Pero parece ser que a nivel popular la gente identifica la inestabilidad familiar como una causa, aunque a nuestro juicio puede ser conceptuada como una consecuencia.

La mayor parte de los encuestados, el 67 por ciento conocen compatriotas que han emigrado a otros

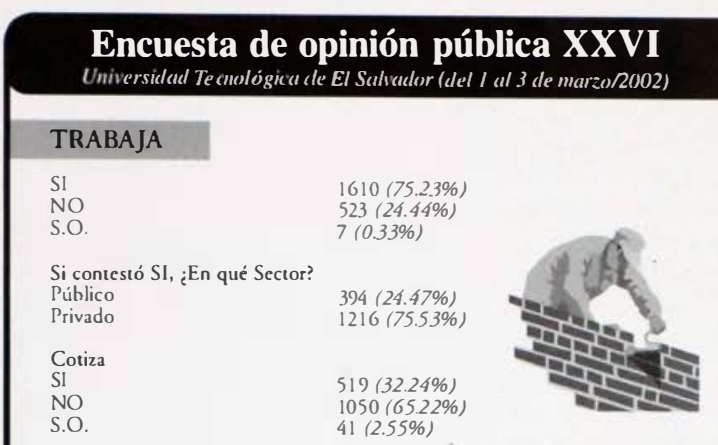

¿Cuál es el ingreso promedio mensual en su hogar?

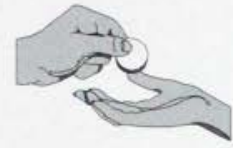

Menos de e 2500.

De $c 2500$ a $₫ 5000$

De $₫ 5000$ a $₫ 7500$

Más de $\subset 7500$.

Sin Opinión

$1381(64.53 \%)$

$524(24.49 \%)$

$111(5.19 \%)$

$53(2.48 \%)$

$71(3.32 \%)$

Seleccione los problemas más graves que enfrenta nuestro país

$\begin{array}{ll}\text { BLOQUE "A" } & \\ \text { Todo caro } & 1377(32.37 \%) \\ \text { Educación } & 500(11.75 \%) \\ \text { Escasez de agua } & 380(8.93 \%) \\ \text { Maras } & 769(18.08 \%) \\ \text { Alcoholismo y Drogadicción } & 489(11.50 \%) \\ \text { Secuestros } & 728(17.11 \%) \\ \text { Ninguno } & 6(0.14 \%) \\ \text { S.O. } & 5(0.12 \%) \\ & \\ \text { BLOQUE "B" } & 1478(34.73 \%) \\ \text { Salarios bajos } & 513(12.05 \%) \\ \text { Salud } & 528(12.41 \%) \\ \text { Contaminación } & 1188(27.91 \%) \\ \text { Delincuencia } & 160(3.76 \%) \\ \text { Estado de carreteras } & 375(8.81 \%) \\ \text { Contrabando } & 6(0.14 \%) \\ \text { Ninguno } & 8(0.19 \%) \\ \text { S.O. } & \\ \text { BLOQUE "C" } & 1649(39.00 \%) \\ \text { Desenpleo } & 461(10.90 \%) \\ \text { Vivicnda } & 368(8.70 \%) \\ \text { Deforestación } & 342(8.09 \%) \\ \text { Narcotráfico } & 1024(24.22 \%) \\ \text { Corrupción } & 358(8.47 \%) \\ \text { Transporte } & 13(0.31 \%) \\ \text { Ninguno } & 13(0.31 \%) \\ \text { S.O. } & \\ & \end{array}$
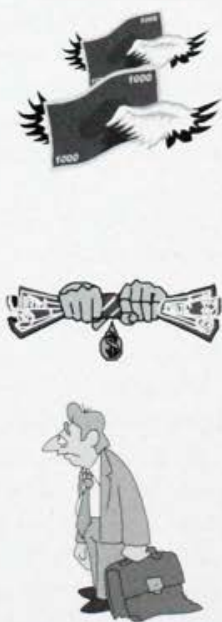
paísesen los últimos años. El alto valor de esta pregunta nos da la impresión que la migración se ha convertido en una opción frecuente para los salvadoreños. La pregunta obligada es ¿Qué los impulsa a tomar una decisión tan trascendental como para abandonar su tierra, su familia, su estabilidad, y ese sentimiento que vincula al hombrecon su parria? ¿Será el desempleo? ¿La falta de oportunidades? ¿La creencia de que aquí ya no es posible hacer nada y es preciso buscar nuevos horizontes?.

Los motivos se encuentran en el fondo de la decisión de cada migrante, pero a nivel social el problema de que dicho fenómeno se ha generalizado y aumentado tanto en los últimos años, es sintomático y preocupante. Deberíamos preguntarnos si El Salvador no se quedaría deshabitado si los norreamericanos concedieran visa a todos los que se quisieran ir. En Cuba sucedería lo mismo, y el hecho de que se pregone a los cuatro vientos que tenemos una ejemplar democracia no cambia el instinto de la huida. Por eso es que en opinión de la gente la causa de la emigración es el desempleo en un 78 por ciento.

Al priorizar los hechos de la delincuencia, los delitos que más sensiblemente nos af ectan en su orden de importancia son: los robos $y$ asaltos, los secuestros, las maras y las violaciones. Una sociedad insegura, con un débil control policial, pero a pesar de ello se evalúa a la Policia Nacional Civil como eficiente en un 55 por ciento. Contradictorio y fuera de lógica, especialmente si de acuerdo con las respuestas las personas opinan que la delincuencia sigue igual ( 40 por

\section{Encuesta de opinión pública XXVI \\ Universidal Te chológica de El Salvador (del I al 3 de marzo/2002)}

¿A qué religión pertenece?

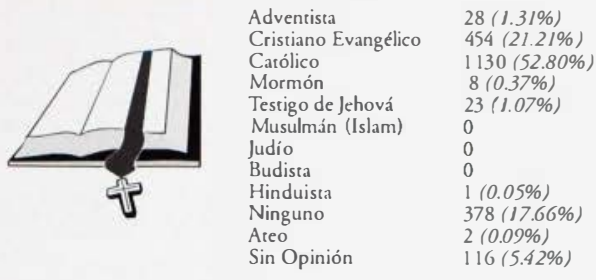

¿Cree que el Gobierno está resolviendo los problemas que mencionó? $\begin{array}{ll}\text { SI } & 492(22.99 \%) \\ \text { NO } & 1559(72.85 \%) \\ \text { S.O. } & 89(4.16 \%)\end{array}$

Sí contestó NO, seleccione una causa por la cuál considera que el Gobierno no está resolviendo los problemas antes mencionados

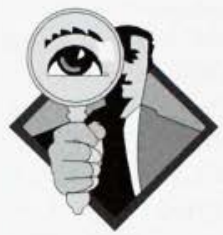

Problemas muy complejos Incapacidad para gobernar

No le importan los problemas del pueblo 622 (39.90\%)

No lo dejan los otros partidos políticos 233 (14.95\%)

S.O.
¿Cuál considera que es la causa principal de la delincuencia en el pais?

$\begin{array}{ll}\text { Desintegración familiar } & 698(32.62 \%) \\ \text { Desempleo } & 932(4355 \%) \\ \text { Carencia de Valores Morales } & 203(9.49 \%) \\ \text { Débil legislación } & 96(4.49 \%) \\ \text { Alcoholismo y Drogadicción } & 129(6.03 \%) \\ \text { Deportación de los EE.UU. } & 59(2.76 \%) \\ \text { S.O. } & 23(1.07 \%)\end{array}$

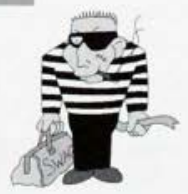

¿Cómo considera el desempeño de la PNC en su lucha contra la delincuencia?

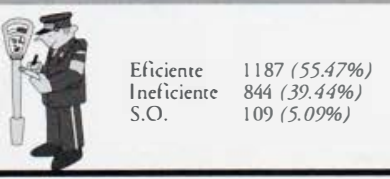


ciento) $y$ ha aumentado (33 por ciento). Si sumamos ambos valores, por exclusión solo el 27 por ciento de las opiniones respaldan esa calificación de eficiencia. Sin duda las matemáticas simples son a veces confusas.

El 57 por ciento de la población entrevistada opina que esta sarisfecha con el servicio del transporte público y se señalan como los problemas más importantes: que los cobradores $y$ motoristas maltratan a los pasajeros (30 por ciento), que se irrespetan las señales de tránsito (25 por ciento) y que las unidades van muy llenas de gente (16\%). Todos los problemas están relacionados directamente con la conducta de choferes y cobradores más que con los empresarios. Posiblemente la gente cree que recibe un servicio necesario pero de mala calidad humana; $y$ se niegan en un 52 por ciento a pagar más por el pasaje. No se pueden hacer conclusiones con datos tan escasos, pero si puede señalarse una preocupación evidente por el incremento de los gastos familiares cuando los ingresos son insuficientes, y como se decía al inicio de la encuesta, cuando la vida está cara.

Cuando se pregunta a quién beneficiaría el nuevo sistema de transporte público hay una posición innegable: posiblemente a cualquiera, pero menos al usuario. Solamente un 6 por ciento de bien intencionados ciudadanos creen que ellos van a ser beneficiados por el nuevo sistema; los demás creen que serán los empresarios (29\%), los distribuidores de buses (16\%) y el gobierno (27\%).

La encuesta insiste nuevamente en la situación familiar: el costo de la

\section{Encuesta de opinión pública XXVI Universidad Tecnológica de El Salvador (alel I al.3 de maros/2002)}

Si contestó Ineficiente, ¿̇A qué se debe? l.a Dirección

Mandos Superiores (Comisionados/ Inspectores) Corrupción interna en la l'NC.

Selección y formación de alumnos en la Academia Poca capacitación

Falta de recursos materiales y equipo.

Pocospoliclas

S.O.
$89(10.55 \%)$
$102(12.09 \%)$
$363(43.01 \%)$
$45(5.33 \%)$
$103(12.20 \%)$
$71(8.41 \%)$
$43(5.09 \%)$
$28(3.32 \%)$

\section{¿Considera que El Salvador vive momentos de crisis ?}

$\begin{array}{ll}\text { SI } & 1898(88.69 \%) \\ \text { NO } & 206(9.63 \%) \\ \text { S.O. } & 36(1.68 \%)\end{array}$

Si contestó SI, ¿ A qué se debe?

Aspectos Económicos

Aspectos Sociales

Aspectos Politicos

Desastres Naturales (Terremotos) 265 (13.96\%)

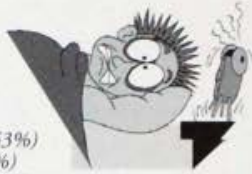

$1016(53.53 \%)$

$181(9.54 \%)$

S. O.

$27(1.42 \%)$

¿Conoce de salvadoreños que han emigrado a otros países en los últimos dos años?

$\begin{array}{ll}\text { I. SI } & 1436(67.10 \%) \\ \text { 2. NO } & 691(32.29 \%) \\ \text { 3. S.O. } & 13(0.61 \%)\end{array}$

Si contestó $\mathrm{SI}$ ¿ Por qué emigraron?

Desempleo

$1120(77.99 \%)$

Delincuencia

$82(5.71 \%)$

Familiares en el extranjero

Temor a los desastres naturales

Pesimismo al futuro de nuestro pais

S.O.

$102(7.10 \%)$

$22(\mathrm{I} .53 \%)$

$99(6.89 \%)$

$11(0.77 \%)$
Seleccione en orden de prioridad los 2 tipos de delincuencia que más afectan a la sociedad.

$\begin{array}{ll}\text { Robos y asaltos } & 1.320(31.13 \%) \\ \text { Secuestros } & 1161(27.38 \%) \\ \text { Narcotráfico } & 422(9.95 \%) \\ \text { Contrabando } & 207(4.88 \%) \\ \text { Violaciones } & 528(12.45 \%) \\ \text { Maras } & 584(13.77 \%) \\ \text { Ninguno } & 3(0.07 \%) \\ \text { S.O. } & 15(0.35 \%)\end{array}$

\section{Comparado con el año pasado ¿ Cómo} considera el nivel de la delincuencia?

$\begin{array}{ll}\text { Han disminuido } & 514(24.02 \%) \\ \text { lgual } & 855(39.95 \%) \\ \text { H.an aumentado } & 712(33.27 \%) \\ \text { S.O. } & 59(2.76 \%)\end{array}$

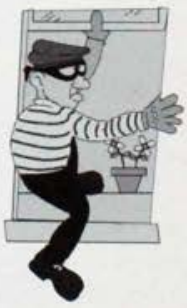


vida en relación con el año pasado se considera igual o mayormente grave en un 91 por ciento.' Por eso no extraña que el 87 por ciento crean que la situación económica de su hogar no ha mejorado sino que se deteriora, y de nuevo, insistentemente el desempleo aparece como una causa muy sentida. El 50 por ciento de los hogares cuentan con personas desempleadas.

¿Estarán equivocados los ciudadanos cuando expresan que el gobierno no hace nada por ayudarles a resolver sus mayores problemas? Aunque en este país no se dispone de estadísticas veraces para medir estos fenómenos; pese a los desplegados propagandísticos oficiales la gente se sigue preguntando donde estarán los empleos. El Banco Central da como cifra cierta un crecimiento de la economia de un 1.8 por ciento. Deberíamos de tener una explicación consecuente ¿porqué el empleo aumenta en una economía que crece?

Lo más preocupante es que el número de desempleados en cada grupo familiar, entre 1 a 3 por familia, agrega una cifra de 89 por ciento. ${ }^{2}$ Luego cuando se detecta que el 78 por ciento de los desempleados forzosos tienen entre 6 meses y más de un año de no encontrar trabajo hay que preocuparse, porque no se trata de desempleo temporal sino que estructural; a no ser que se quiera calificarlos como haraganes que no quieren trabajar.

Los resultados de la encuesta indican que para el 78 porciento de la población el uso del dólar como moneda no ha contribuido a mejorar la economía y además que ese mismo

\section{Encuesta de opinión pública XXVI \\ Universidad Te cnologica de El Salvador (del l al 3 de marzo/2002)}

¿Es usuario del transporte público?

SI $1738(81.21 \%)$

NO $\quad 387(18.08 \%)$

S.O. $15(0.70 \%)$

Si contestó SÍ , Está satisfecho con el servicio que le

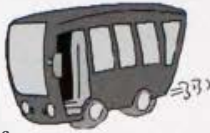

brinda el transporte público actualmente?

SI $993(57.13 \%)$

NO $\quad 686(39.47 \%)$

S.O. $59(3.39 \%)$

Si contestó NO, ¿'’or qué no está satisf echo?

Los buses-microbuses van muy llenos

Mucho se tardan en las paradas $\quad 84(12.24 \%)$

Manejan muy rápido $\quad 57(8.31 \%)$

No respetan las señales de cránsito $\quad 44$ (6.41\%)

Mal estado de las unidades de transporte $170(24.78 \%)$

S.O.

$12(1.75 \%)$

Cree que con el nuevo Sistema de Transporte Público habrá incremento del pasaje?

$\mathrm{SI}$

NO

S.O

$1163(66.92 \%)$

$457(26.29 \%)$

$118(6.79 \%)$

Estaría dispuesto a pagar más, si el servicio del transporte público mejorara?

$\mathrm{SI}$

NO

$786(45.22 \%)$

$900(51.78 \%)$

$52(2.99 \%)$

A quién beneficiará el Nuevo Sistema de Transporte Público?

A los empresarios dueños de autobuses

A las discribuidoras de autobuses

Al Gobierno

Al usuario

No sabe

S.O.

$46(2.15 \%)$

Comparado con el año anterior, ¿Cómo considera el costo de la vida?

Menor $\quad 162(7.57 \%)$

Igual $\quad 668(31.21 \%)$

Mayor $1285(60.05 \%)$

S. O. $\quad 25(1.17 \%)$

¿Cómo considera la situación económica de su hogar en relación al año pasado?

$\begin{array}{ll}\text { Mejor } & 226(10.56 \%) \\ \text { lgual } & 997(46.59 \%) \\ \text { Peor } & 894(41.78 \%) \\ \text { S.O. } & 23(1.07 \%)\end{array}$

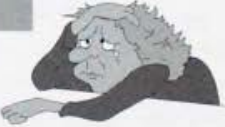

¿En su hogar ¿Existen personas desempleadas?

$\begin{array}{ll}\text { SI } & 1067(49.86 \%) \\ \text { NO } & 1043(48.74 \%) \\ \text { S.O. } & 30(1.40 \%)\end{array}$


segmento de la población no está de acuerdo con que desaparezca el colón. Esta opinión constituye un serio revés a la propaganda oficial que insiste en los beneficios de la economía dolarizada y en la supuesta gran aceptación que la medida ha tenido en la población. Pareciera ser que si no se hubiera impuesto dicha medida usando los instrumentos de presión de los que dispone el gobierno y se hubiera optado por ser más democráticos en su implementación, la masa circulante de dólares podría ser mucho menor.

Hay indicadores de que la gente cree que la principal gestión del gobierno para mejorar la economía del país se centra en la construcción de carreteras $y$ viviendas en un $\mathbf{4 6}$ por ciento, luego señalan la generación de empleos con un 18 por ciento y la apertura para las inversiones extranjeras con otros 18 por ciento. Las respuestas son inconsistentes, y en lo que respecta a generación de empleos e inversiones extranjeras las cifras reales disponibles, a nivel nacional, indican codo lo contrario. Si alguna explicación puede obtenerse es que la demagogia publicita ria sobre la gestión oficial está obteniendo sus frutos, pues estos son los temas con los que se ataca al grueso dela población que no tiene capacidad para discernir estos remas, para demostrar el éxito de la gestión.

Para muchos el Presidente de la República hace algunos acercamientos de concertación con otros sectores de la vida nacional, entre ellos destacan la gran empresa en un 20 por ciento, las alcaldias en un 12 por ciento y la industria en otro 12 por ciento. Es claro que se percibe la afinidad del gobierno con los sectores que le brindan un

\section{Encuesta de opinión pública XXVI \\ Universidad Tecuológica de EI Salvador (del I al 3 de marza/2002)}

Si contesto Sí, ¿Cuántas?

UNO

DOS

$358(33.55 \%)$

IRES

$341(31.96 \%)$

CUAIRO

$251(23.52 \%$

MAS IDE $4 \quad 42(3.94 \%$

S. O. $11(1.03 \%)$

¿Cuánto tiempo tienen de estar desempleadas estas personas?

Menos de 6 meses $221(20.71 \%)$

Más de 6 meses $327(30.65 \%)$

Mís de 1 año $\quad 509(47.70 \%)$

S.O. $10(0.94 \%)$

¿Considera que el uso del dólar ha mejorado la economía del país?

$\begin{array}{ll}\text { SI } & 405(18.93 \%) \\ \text { NO } & 1635(76.40 \%) \\ \text { S.O. } & 100(4.67 \%)\end{array}$

: Estai de acuerdo que desaparezca el Colón?

SI $424(19.81 \%)$

NO $\quad 1676(78.32 \%)$

S.O. $40(1.87 \%)$

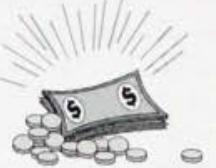

18.- Después de haberse implementado el uso del dólar, ¿ Ha logrado adaptarse a la conversión de las dos monedas y al mancjo del cambio fraccionario?

SI $\quad 1221(57.06 \%)$

NO $890(41.59 \%)$

S.O. $29(1.36 \%)$

¿Cuál considera que es la principal gestión que ha realizado el Gobierno para mejorar la economía del país?

El bimonetarismo o implementación del uso del dólar.

La gestión de préstamos internacionales.

$221(10.33 \%)$

Generación de fuentes de trabajo.

$295(13.79 \%$

Gestión de estadia de los salvadorénos en los E.U. (TPS) $\quad 426(19.91 \%)$

Tratados Internacionales (TLC. ICC, ALCA) $332(15.51 \%)$

Eliminación de los subsidios (agua. electricidad y combustibles) 164 (7.66\%)

Ninguno

$348(16.26 \%)$

S.O

$121(5.65 \%)$

De las siguientes instituciones, ¿Cuál considera que ha desarrollado mejor su función en estos últimos dos años y medio?

Corte Suprema de Justicia

Asamblea Legislativa

Presidencia de la República

$170(7.94 \%)$

Fiscalia General de la República

$44(6.73 \%)$

$174(8.13 \%)$

$166(7.76 \%)$

PNC

$510(23.83 \%)$

Procuraduria para la Defensa de los Derechos Humanos 332 (I5.51\%)

Fucra Armada

$185(8.64 \%)$

Ninguna

S.O.

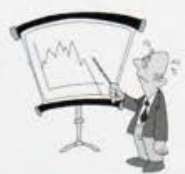

$99(4.63 \%)$ 
significarivo apoyo político como lo son la gran empresa y los industriales; pero en el verdadero sentido del tirmino esto no puede considerarse como concertación puesto que pertenecen al mismo bando. Se concerta con el enemigo, con la oposición, o con los sectores políticamente adversos y aquí las cifras indican por su peso, que realmente no hay ninguna concertación.

Cuando se detallan las características personales del Presidente Flores de como la población lo percibe, las encuestas indican que se le considera capaz en un 58 por ciento, comunicativo en un 59 por ciento. popular en un 60 por ciento. concertador en un 44 por ciento y con un definido liderazgo en un 52 por ciento. En términos generales es una buena evaluación, en ese sentido la imagen del Presidente es aceptada por una significativa cantidad de ciudadanos; por lo que no es de extrañar que la puntuación de su gestión entre 5 a 7 puntos se encuentre avalada por el 45 por ciento de los encuestados.

En cuanto al desempeño de los ministros del gobierno la calificación más favorable le fue otorgada a la cartera de Educación con un 30 por ciento a su favor; luego la de Defensa con el 18 por ciento, Obras Públicas con el 11 por cienro y Salud con el 10 por ciento. Es muy difícil medir si las opiniones de una encuesta tienen los elementos valorativos suficientes para hacer una evaluación mesurada y consistente de las labores de estos ministerios o si se debe a la mayor o menor presencia de dichos funcionarios en losmedios. La encuesta omite

\section{Encuesta de opinión pública XXVI Universidad Ténológica de E/ Salvalor (del I al _i de marzo/2002)}

¿Cuál considera que es la principal gestión del presidente Francisco Flores para mejorar la economia del país?

Generación de empléos

$101(18.53 \%)$

Reconstrucción nacional (Carreceras y Viviendas) 251 (46.06\%)

Aperturas para inversiones extranjeras

$101(18.53 \%)$

Apoyos Crediticios a la Mediana y Pequeña Empresa 44 (8.07\%)

Disminución de los índices de inflación 19(3.49\%)

S. O.

$29(5.32 \%)$

¿Con qué sectores está concertando más el presidente Francisco Flores?

Partidos políticos de oposición 687 (11.89\%)

Alcaldias

Gran empresa

Mediana y pequeña empresa

Agropecuario

Industria

Comercio

ONG's

Sindicatos

Banca

Ninguno

$750(12.98 \%)$

$1142(19.76 \%)$

$422(7.30 \%)$

$209(3.62 \%)$

$734(12.70 \%)$

$490(8.48 \%)$

$195(3.37 \%)$

$127(2.20 \%)$

$789(13.66 \%)$

$89(1.54 \%)$

S.O

$144(2.49 \%)$

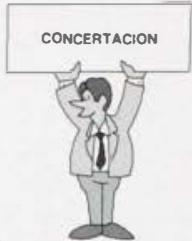

¿Cree que la gestión del Gobierno fortalece el desarrollo de la democracia en el país?

SI $809(37.80 \%) \quad$ NO $1170(54.67 \%) \quad$ S.O. $161(7.52 \%)$

¿Cuáles de las siguientes características considera que posee el Presidente Francisco Flores en el desempeño de sus funciones?

$\begin{array}{llll}\text { Capaz } & & \text { Concertador } & 943(44.07 \%) \\ \text { 1. Si } & 1247(58.27 \%) & \begin{array}{l}\text { 1. Si } \\ 1003(46.87 \%)\end{array} \\ \text { 2. No } & 742(34.67 \%) & \text { 2. No } & 139(6.50 \%) \\ \text { 3. No Sabe } & 83(3.88 \%) & \text { 3. No Sabe } & 55(2.57 \%) \\ \text { 4. S. O. } & 68(3.18 \%) & \text { 4. S. O. } & \\ & & & \\ \text { Comunicativo } & & \text { Liderazgo } & \\ \text { 1. Si } & 1258(58.79 \%) & \text { 1. Si } & 1120(52.34 \%) \\ \text { 2. No } & 753(35.19 \%) & \text { 2. No } & 861(40.23 \%) \\ \text { 3. No Sabe } & 79(3.69 \%) & \text { 3. No Sabe } & 102(4.77) \\ \text { 4. S. O. } & 50(2.34 \%) & \text { 4. S. O. } & 57(2.66 \%)\end{array}$

Popular

1. Si

2. No

3. No Sabe

$274(59.53 \%$

$732(34.21 \%)$

4. S. O.

$81(3.79 \%)$

$53(2.48 \%)$

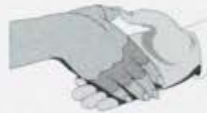

En escala del 1 al 10, ¿Qué nota le asigna al trabajo del Presidente Francisco Flores en estos dos años y medio de gobierno? (Sin Opinión)

$\begin{array}{ll}\text { Uno } & 133(6.21 \%) \\ \text { Dos } & 67(3.13 \%) \\ \text { Tres } & 80(3.74 \%) \\ \text { Cuatro } & 139(6.50 \%) \\ \text { Cinco } & 318(14.86 \%) \\ \text { Seis } & 287(13.41 \%) \\ \text { Siete } & 370(17.29 \%) \\ \text { Ocho } & 295(13.79 \%) \\ \text { Nueve } & 119(5.56 \%) \\ \text { Dicz } & 141(6.59 \%) \\ \text { Sin Opinión } & 191(8.93 \%)\end{array}$


una evaluación de la labor de la Procuraduría de los Derechos Humanos, cuyo papel en los últimos y recientes acontecimientos nacionales ha sido muy importante, independientemente de que estemos o no de acuerdo con ellos.

Hay una actitud social que conviene advertir, el 24 por ciento de la población manifiesta que la mayor credibilidad le merecen las iglesias y en un 19 por ciento los medios de comunicación; las restantes instituciones de la vida pública no les merecen confianza. Llama la atención que las iglesias, que no tienen un papel activo en la política y que no intervienen en los asuntos públicos sean las mejores evaluadas. No podría decirse si este es una distorsión de la encuesta y que se da una confusión en la pregunta, pues no se encuentra el vínculo entre las labores eclesiales y los alcibajos de la política pública.

La nota roja es para los parridos políticos. Nadie les tiene confianza, ni sus propios correligionarios. Esto es grave pues se trata de una crisis de confianza en el sistema político, que se agudiza en la medida que la población se siente frustrada por las actuaciones $y$ las venalidades de sus representantes en el Primer Organo del Estado. La Asamblea no es una institución creible, sin embargo la ponderación que recibe es sumamente discurible: 5 para un 18 por ciento, 6 para un 16 por ciento y 7 para un 14 por ciento. ¿Quién l o creyera?

De la popularidad de ciertos personajes hay mucho que discutir; una de los problemas en este tipo de

\section{Encuesta de opinión pública XXVI} Universidad Téchológica de El Salvador (del I al 3 de marzo/2002)

¿Qué Ministerio está realizando mejor trabajo en la gestión del Presidente Francisco Flores?

$\begin{array}{llll}\text { Educación } & 643(30.05 \%) & \text { Obras Públicas } & 236(11.0 .3 \%) \\ \text { Salud } & 218(10.19 \%) & \text { Agricultura y Ganaderia } & 8(0.37 \%) \\ \text { Trabajo } & 26(1.21 \%) & \text { Medio Ambiente } & 5(0.23 \%) \\ \text { Gobernación } & 39(1.82 \%) & \text { Seguridad Pública } & 33(1.54 \%) \\ \text { Hacienda } & 52(2.43 \%) & \text { Defensa } & 32(1.50 \%) \\ \text { Economía } & 30(1.40 \%) & \text { Ninguno } & 390(18.22 \%) \\ \text { Exteriores } & 24(1.12 \%) & \text { S.O. } & 404(18.88 \%)\end{array}$

¿Aprueba el desempeño de los siguientes funcionarios?
Dra. Beatrice de Carrillo

(Procuradora Derechos Humanos)

1. Si

2. No $\quad 638(29.81 \%)$

3. No lo conoce $444(20.75 \%)$

4. S. O.

$74(3.46 \%)$

Lic. Belisario Artiga (Fiscal General) Dr. Agustín Calderón 1. Sí $823(38.46 \%)$

2. No

3. No lo conoce

$811(37.90 \%)$

$432(20.19 \%)$

4. S. O.

$74(3.46 \%)$

Lic. Mauricio Sandoval

(Director de la PNC)

$\begin{array}{ll}\text { 1. Sí } & 1078(50.37 \%) \\ \text { 2. No } & 724(3383 \%) \\ \text { 3. No lo conoce } & 271(12.66 \%) \\ \text { 4. S. O. } & 67(3.13 \%)\end{array}$

L.ic. W'alter Araujo

(Presidente Asamblea Legislativa)

1. Si 674 (31.50\%)

2. No $1058(49.44 \%)$

3. No lo conoce 331 (15.47\%)

4. S. O. $77(3.60 \%)$

(Presidt. Corte Suprema de Justicia)

1. Si $724(33.83 \%)$

2. No $\quad 827(38.64 \%)$

3. No lo conoce $517(24.16 \%)$

4. S. O. $72(3.36 \%)$

Dr. Héctor Silva

(Alcalde de San Salvador)

1. Si $954(44.58 \%)$

2. No $851(39.77 \%)$

3. No lo conoce $249(11.64 \%)$

4. S. O. $86(4.02 \%)$
¿Por qué partido político votó en las elecciones de marzo/2000?
Alcaldes

Arena

Pcn

Fmln

Pdc

Cdu

Pan

PId

Ppl

Usc

No Votó

Voro Es Secreto

No Recueda

S. O.

$427(19.95 \%)$
Diputados

Arena

Pcn

Fmln

Pdc

Cdu

Pan

PId

Ppl

Usc

No Votó

Voto Es Secreto

No Recueda

S. O.

$496(23.18 \%)$

$68(3.18 \%)$

334 (15.61\%)

$42(1.96 \%)$

$9(0.42 \%)$

$4(0.19 \%)$

$1(0.05 \%)$

0

$630(29.44 \%)$

$69(3.22 \%)$

$23(1.07 \%)$

$464(21.68 \%)$
¿Tiene conocimiento sobre los beneficios que se obtendrán con los TLCs?

SI $466(21.78 \%) \quad$ NO $1619(75.65 \%) \quad$ S.O. $55(2.57 \%)$

Aumentarán Exportaciones

Disminución del costo de los productos

SI $360(77.25 \%)$; NO $106(22.75 \%)$ SI $272(58.37 \%)$ : NO $194(41.63 \%)$

Mayores ingresos al país

Politica de comercio exterior SI $317(68.03 \%)$; NO 149 (31.97\%) SI $290(62.23 \%)$; $\mathrm{NO} 176(37.77 \%)$

Fuentes de trabajo

SI $322(69.10 \%)$; NO 144 (30.90\%)

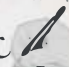


Universidad Tecnológica de El Salvador

encuesta que conlleva un listado de nombres es muy sutil y puede prestarse a interferir en la memoria del encuestado. La verdadera popularidad es aquella que se recuerda sin sugerir nombres, porque en un momenro dado pueden estar los que no son y ser los que no tienen. En este sentido hay una significativa diferencia entre popularidad y credibilidad; que un encuestado señale a un político por los años que tiene de participación, por sus hazañas, $y$ hasta por sus malandanzas no significa necesariamente credibilidad. Posiblemente popularidad si.

Si las elecciones fueran hoy. ¿quién sería el afortunado?. Esto parece un estribillo: ARENA cuenta con 26 por ciento a su favor; el FMLN con 19 por ciento; los demás ni se cuentan. Pero el verdadero ganador son los que no votan y los abstencionistas que en total hacen un respetable 46 por ciento. Hablar de democracia con un pueblo que no vota es un contrasentido; $y$ estos resultados son, y aquí si cabe por los hechos, la escasa credibilidad que tiene nuestra pobre democracia.

\section{Citas}

El 31 por ciento consideran que el costo de la vida es igual que antes, pero el 60 por ciento no duda que el cosro de vida se ha deteriorado.

34 por ciento de los grupos familiares rienen 1 desempleado; 32 por ciento tienen dos y 24 por ciento tienen 3 .

${ }^{3}$ Las ponderaciones aludidas reflejan la situación siguiente: con nota de 5, el 15 por ciento; con 6, el 13 por ciento y con $7, \mathrm{el} 17$ por ciento.

\section{Encuesta de opinión pública XXVI Universidad Teanológica de El Salvador (del I al 3 de marzo/2002)}

De las siguientes personas o instituciones ¿Quiénes le merecen mayor credibilidad?

$\begin{array}{llll}\text { Medios de Comunicación } & 1074(19.21 \%) & \text { Dipurados } & 121(2.16 \%) \\ \text { Jueces } & 300(5.37 \%) & \text { PNC } & 657(11.75 \%) \\ \text { Iglesias } & 1340(23.97 \%) & \text { PDDH } & 370(6.62 \%) \\ \text { Fiscalia } & 402(7.19 \%) & \text { Alcaldes } & 238(4.26 \%) \\ \text { Partidos Políticos } & 140(2.50 \%) & \text { Ninguno } & 166(2.97 \%) \\ \text { Fuerza Armada } & 499(8.93 \%) & \text { S.O } & 38(0.68 \%)\end{array}$

ONG's $246(4.40 \%)$

De los siguientes partidos políticos, ¿Aprueba el desempeño de sus diputados?

$\begin{array}{llll}\text { ARENA } & & \text { PDC } & \\ \text { SI } & 869(40.61 \%) & \text { SI } & 528(24.67 \%) \\ \text { NO } & 1114(52.06 \%) & \text { NO } & 1439(67.24 \%) \\ \text { S.O. } & 157(7.34 \%) & \text { S.O. } & 173(808 \%) \\ \text { PCN } & & \text { CDU } & \\ \text { SI } & 574(26.82 \%) & \text { SI } & 451(21.07 \%) \\ \text { NO } & 1415(66.12 \%) & \text { NO } & 1512(70.65 \%) \\ \text { S.O } & 151(7.06 \%) & \text { S.O. } & 177(8.27 \%) \\ \text { FMLN } & & \text { PAN } & \\ \text { SI } & 651(30.42 \%) & \text { SI } & 326(15.23 \%) \\ \text { NO } & 1321(61.73 \%) & \text { NO } & 1601(74.81 \%) \\ \text { S.O. } & 168(7.85 \%) & \text { S.O. } & 213(9.95 \%) \\ \text { P.O } & & & \end{array}$

En escala de 1 a 10 , ¿Qué nota le asigna al trabajo realizado por la Asamblea Legislativa?

$\begin{array}{llll}\text { Uno } & 132(6.17 \%) & \text { Siete } & 309(14.44 \%) \\ \text { Dos } & 84(3.93 \%) & \text { Ocho } & 203(9.49 \%) \\ \text { Tres } & 109(5.09 \%) & \text { Nueve } & 60(2.80 \%) \\ \text { Cuatro } & 157(7.34 \%) & \text { Diez } & 59(2.76 \%) \\ \text { Cinco } & 384(17.94 \%) & \text { Sin Opinión } & 292(13.64 \%) \\ \text { Seis } & 351(16.40 \%) & & \end{array}$

De las siguientes personalidades, ¿Quién le merece mayor credibilidad?
BLOQUE A

Shafick Handal

Francisco Jovel

Héctor Silva

Oscar Ortiz

$97(4.53 \%)$

Ninguno

S.O.

BLOQUE B

Rubén Zamora

René Aguiluz

Ciro Cruz Zepeda

Mauricio Meyer

Gloria Salguero Gross

Ninguno

S.O.

$376(17.57 \%)$
$164(7.66 \%)$
$585(27.34 \%)$
$97(4.53 \%)$
$90(4.21 \%)$
$734(34.30 \%)$
$94(4.39 \%)$
$472(22.06 \%)$
$141(6.59 \%)$
$214(10.00 \%)$
$230(10.75 \%)$
$278(12.99 \%)$
$719(33.60 \%)$
$86(4.02 \%)$

\section{BLOQUE C}

Walter Araujo $304(14.21 \%)$

Roberto Murray Meza 268 (12.52\%)

Tony Saca $\quad 467(21.82 \%)$

Gerardo Suvillaga $73(3.41 \%)$

Milena de Escalón $156(7.29 \%)$

Ninguno $\quad 778(36.36 \%)$

S.O.

$94(4.39 \%)$
Si las elecciones fueran este día ¿ Por cuál Partido Político votaría?

$\begin{array}{llll}\text { ARENA } & 553(25.84 \%) & \text { FUERZA } & 3(0.14 \%) \\ \text { PCN } & 94(4.39 \%) & \text { No votará } & 481(22.48 \%) \\ \text { FMLN } & 414(19.35 \%) & \text { Voto es Secreto } & 50(2.34 \%) \\ \text { PDC } & 65(3.04 \%) & \text { No sé/Indeciso } & 64(2.99 \%) \\ \text { CDU } & 16(0.75 \%) & \text { S. O. } & 399(18.64 \%)\end{array}$

$\quad 16(075$

$1(0.05 \%)$ 